\title{
Escola rural i territori: una simbiosi clau
}

\section{Laura Domingo Peñafiel *}

Recepció original: 21 d'abril de 2020

Acceptació: 27 de juliol de 2020

Publicació: 16 de desembre de 2020

La revista Temps d'Educació ha dedicat diversos articles a l'educació en el món rural. Antoni Tort Bardolet, professor de la Universitat de Vic-Universitat Central de Catalunya, ja escrivia l'any 1995 sobre renovació pedagògica i territori fent referència a les Zones Escolars Rurals (ZER), en aquell moment un model pedagògic i organitzatiu que tenia només cinc anys de vida. Posteriorment, I'any 1998, en Jordi Feu Gelis, professor de la Universitat de Girona, va publicar un article sobre el sentit de l'escola rural en un món que es desruralitza. Més endavant, a cavall dels anys 2001 i 2002, concretament el número 26 d'aquesta revista va estar dedicat al monogràfic Educació, ruralitat i territori: la construcció d'una identitat pròpia coordinat per la professora de la Universitat de Barcelona, Roser Boix Tomàs. En aquest ja s'alertava de la necessitat de situar la ruralitat des de l'òptica del canvi tenint en compte la redefinició del món rural i de «construir una escola rural fortament implantada al territori, adequada a la necessitat dels seus habitants, cohesionada socialment i cultural i participativa, per fer front als reptes de futur que la nostra societat té plantejats» (p. 120). Ja som en aquell futur al qual es feia referència i gairebé vint anys després, el present monogràfic pretén explorar i ressituar l'escola rural en relació al territori i, per fer-ho, es presenten els resultats d'algunes de les últimes recerques d'àmbit espanyol i europeu sobre la temàtica.

Aquest monogràfic aplega sis articles de recerca: tres corresponen a un mateix projecte; un quart, molt centrat en els resultats de diferents proves estandarditzades d'avaluació de la qualitat educativa en les zones rurals; i per acabar, dos articles fruït de tesis doctorals centrades en explorar el paper de l'escola rural com a factor d'arrelament i dinamitzador del territori, un des del punt de vista dels agents que hi intervenen i el segon, des de la perspectiva de la construcció de la identitat rural.

Els tres primers articles que es presenten s'emmarquen en el projecte «La Formación profesional y las competencias del maestro rural como dinamizador de la dimensión territorial en la escuela (FOPROMAR)» finançat pel programa Erasmus+ de la Unió Europea i desenvolupat entre els anys 2017-2019. Aquest tenia com a finalitat principal proposar un pla de formació permanent i unes propostes de formació inicial per millorar les competències professionals del professorat d'escoles rurals dels següents països: Portugal (Alto Alentejo), Espanya (Catalunya i Aragó), i França (Aquitània). En aquest monogràfic es mostren tres articles, dos corresponents a resultats d'Espanya i un de Portugal.

En el primer article, els professors de la Universitat de Barcelona, Roser Boix Tomàs i Francesc Buscà Donet, mitjançant un estudi exploratori efectuat a partir d'enquestes a mestres rurals catalans, detecten la necessitat d'enfortir la dimensió territorial en els plans

$\left(^{*}\right)$ Professora investigadora del Departament de Pedagogia de la FETCH (Facultat d’Educació, Traducció i Ciències Humanes) a la UVic-UCC. El seu àmbit d'estudi és l'educació al món rural. Adreça electrònica: laura.domingo@uvic.cat 
de formació inicial dels graus de mestre desenvolupant competències d'àmbit pedagògic, metodològic i de relació escola-comunitat. La recerca mostra que caldria incloure les característiques culturals del territori rural a la planificació docent incorporant l'ús de les TIC, així com establir processos de participació entre l'escola-família-comunitat fent que l'escola tingui com a objectiu donar servei al desenvolupament cultural del seu territori rural. També caldria possibilitar accions de desenvolupament professional per al professorat del centre en relació a aquestes necessitats detectades. La recerca també concreta quins són els sabers relacionats amb la dimensió territorial que caldria reforçar en els plans de formació ja que els mestres afirmen que en tenen poc coneixement. Alguns són, per exemple, la literatura, proverbis i festes populars, el coneixement d'altres institucions locals, el patrimoni natural i immoble, l'ecologia, etc.

En segon Iloc, Juan Lorenzo Lacruz, Pascual Rubio Terrado i Pilar Abós Olivares, tots tres professors de la Universitat de Saragossa, ofereixen un mapeig de l'escola rural a una de les províncies més despoblades d'Espanya, Terol. L'article realitza un repàs legislatiu, el canvi de conceptualització en quant a la cultura rural i defensa la necessitat que l'escola rural tingui un paper vertebrador sòciocultural i d'innovació. També, fruit dels resultats del projecte FOPROMAR, dona visibilitat a un seguit de pràctiques innovadores entre escoles rurals i el seu territori des del punt de vista de la justícia social.

Antonio M. Duarte i Filipe C. Mesquita, professors de la Universitat de Lisboa, i també en el marc del projecte europeu esmentat mostren, a partir dels resultats d'unes enquestes passades a cent seixanta-un mestres rurals portuguesos, la necessitat de formació dels mestres en relació a la competència cultural. Tenint en compte aquesta, els resultats suggereixen que la formació hauria de contemplar les característiques culturals del territori local a I'hora de planificar; vincular el contingut del programa d'estudis amb la cultura dels estudiants; utilitzar els recursos culturals del territori local; desenvolupar els coneixements dels estudiants sobre la cultura local i la diversitat cultural; procurar el desenvolupament cultural del territori local; vincular-se a les iniciatives socioculturals de la comunitat; i per últim, utilitzar l'escola com a espai cultural de la comunitat local.

El quart article ha estat escrit per Rogeli Santamaria Luna, doctor investigador i inspector d'educació de Castelló de la Plana. Aquest exposa diferents resultats d'aprenentatge dels alumnes de les escoles rurals a partir de proves i instruments d'avaluació. Per exemple, una dada positiva és que PISA 2018 mostra que els alumnes rurals espanyols valoren més la tasca docent dels mestres que els alumnes de les escoles urbanes. Aquests elements ens donen pistes sobre les potencialitats de l'escola rural però l'article també aborda els punts febles, com per exemple que els alumnes rurals tenen les expectatives més baixes pel que fa a cursar estudis superiors. Els resultats també indiquen que l'escolarització en una escola rural «deixa petjada», la qual cosa ajuda a la seva escolarització posterior a secundària. Una informació molt valuosa per seguir aprofundint-hi.

Elisabetta Tomazzoli, doctora per la Universitat de Bolzano, presenta resultats de la seva tesi doctoral realitzada a partir d'una mostra intencional de catorze escoles rurals italianes de zones geogràfiques molt diferents però totes amb un element en comú: agents de la comunitat compromesos que creuen en l'escola rural com a motor de desenvolupament de la comunitat. L'article mostra que la potencialitat de l'escola rural no és per motius estructurals com l'entorn geogràfic o els recursos demogràfics o econòmics, sinó que pel paper crucial del mestre com a «intel.lectual orgànic» que té la funció de pont entre la cultura i la comunitat. L'autora explora el concepte d'educació comunitària 
com un espai en el que les nenes i nens experimenten la participació social i es formen en valors democràtics i cooperatius.

I per acabar, un article en el que ha col-laborat Guillem Riba Duarte, doctorand del Departament de Pedagogia de la Universitat de Vic-Universitat Central de Catalunya, en què presenta els primers resultats de la tesi doctoral que té com a objectiu explorar la construcció de la identitat rural des del punt de vista de l'escola rural com a element d'arrelament i revitalització territorial. Aquesta recerca narrativa es basa en una història de vida d'un jove pirinenc i els primers resultats contribueixen a comprendre les raons que han portat al subjecte a retornar i restablir-se al seu poble d'origen. Motius relacionats amb l'escola rural on va estudiar i que actua com a motor de revitalització territorial promovent la continuïtat demogràfica de la població rural.

En resum, doncs, aquest monogràfic, tot i que mostra algunes experiències reeixides entre l'escola rural i el territori existents, pretén alertar de la necessitat de millorar la competència cultural i la dimensió territorial dels mestres rurals així com dels estudiants de mestre en la formació inicial. Malgrat que actualment no existeix un perfil específic de mestre rural en els plans d'estudi de mestre de Catalunya ni d'Espanya, els resultats de les diferents recerques assenyalen que són els mateixos mestres els que reconeixen que els falta coneixements propis del territori. Tenint en compte el paper cabdal de l'escola rural com a agent clau en la dinamització del territori i en el sentit de pertinença i d'arrelament dels infants, és urgent tenir mestres rurals compromesos amb el seu entorn. I és que el primer pas és conèixer, per després estimar i d'aquesta manera, cuidar.

\section{Referències}

Boix i Tomàs, R. (2002) «Presentació: Educació, Ruralitat i Territori: La construcció d'una identitat pròpia». Temps d'Educació, 26, p. 119-20. Recuperat de: https://www.raco.cat/index.php/TempsEducacio/article/view/126343 [Consulta: 1 de juliol de 2020].

Feu i Gelis, J. (1998) «La transformació del món rural: el sentit de "l'escola rural" en un món que es desrulalitza». Temps d'Educació, 20, p. 287-14. Recuperat de: https://www.raco.cat/index.php/TempsEducacio/article/view/125839 [Consulta: 1 de juliol de 2020].

Tort i Bardolet, A. (1995) «Renovació pedagògica i territori». Temps d'Educació, 14, p. 18594. Recuperat de: https://www.raco.cat/index.php/TempsEducacio/article/view/ 125606 [Consulta: 1 de juliol de 2020] 